\title{
Modul Gateway Pada Simulasi Persimpangan Lalu Lintas
}

\author{
Gateway Module on The Simulation of Traffic Junction \\ Erwin Harahap*, Farid H Badruzzaman, Yurika Permanasari, Didi Suhaedi \\ Program Studi Matematika, FMIPA, Universitas Islam Bandung \\ erwin2h@unisba.ac.id
}

\begin{abstract}
Abstrak. Kepadatan lalu lintas seringkali terjadi dipersimpangan jalan raya, khususnya persimpangan dengan lampu lalu lintas. Durasi waktu lampu lalu lintas, yaitu lampu merah dan hijau, apabila dilakukan pengaturan secara tepat sesuai dengan kepadatan lalu lintas dapat mengurangi kepadatan. Beberapa masalah yang terjadi pada persimpangan lalu lintas adalah jalan raya adalah tidak terjadinya keseimbangan panjang antrian pada setiap jalur. Pada artikel ini, kami mengusulkan sebuah modul simulasi yang dapat digunakan untuk mensimulasikan persimpangan dengan lampu lalu lintas menggunakan aplikasi MATLAB SimEvents. Modul yang diusulkan adalah berupa modul gateway dimana entitas tidak mengalir selama durasi waktu tertentu yang diatur melalui coding program. Melalui simulasi ini diharapkan dapat dilakukan pemilihan durasi waktu yang tepat sehingga diperoleh keseimbangan panjang antrian di setiap jalur di persimpangan.
\end{abstract}

Kata kunci: persimpangan, lalu lintas, modul simulasi, simevents, MATLAB

\begin{abstract}
Traffic density often occurs at the intersection of highways, especially intersections with traffic lights. The duration of the traffic lights, namely red and green lights, if properly adjusted according to traffic density can reduce density. Some of the problems that occur at traffic junctions are highways, where there is no balance in the length of the queue on each lane. In this article, we propose a simulation module that can be used to simulate intersections with traffic lights using the MATLAB SimEvents application. The proposed module is in the form of a gateway module where the entity does not flow for a certain duration of time regulated through the coding program. Through this simulation, it is expected to be able to select the right time duration so that the balance of the length of the queue in each path at the intersection is obtained.
\end{abstract}

Keywords: intersections, traffic, simulation modules, simevents, MATLAB

\section{Pendahuluan}

Jumlah kendaraan di kota-kota besar di Indonesia semakin meningkat tiap tahunnya. Hal ini tidak sebanding dengan ketersediaan kapasitas jalan raya yang mengakibatkan pada padatnya lalu lintas dan terjadi kemacetan di berbagai tempat [1]. Melihat dari kondisi tersebut, diperlukan solusi yang efektif untuk memecahkan permasalahan kemacetan lalu lintas, dimana salah satunya adalah dengan peningkatan manajemen lampu lalu lintas di persimpangan jalan raya [2]. Lampu lalu lintas di persimpangan jalan raya dipergunakan untuk mengatur lalu lintas pada disetiap jalur untuk bergerak secara bergiliran agar tidak terjadi kemacetan. Namun seringkali muncul permasalahan dimana pengaturan durasi waktu lalu lintas yang tidak tepat dapat menyebabkan antrian kendaraan yang sangat panjang pada salah satu jalur dan antrian pendek atau bahkan tidak ada antrian pada jalur lainnya. Hal ini didasarkan pada pengamatan penulis pada salah satu persimpangan di kota Bandung, yaitu di persimpangan lalu lintas Buah-batu - Soekarno Hatta yang seringkali tidak seimbang. Oleh sebab itu, perlu disusun sebuah metode untuk mengatur durasi lampu lalu lintas agar jumlah antrian optimal dan seimbang.

Dalam artikel ini diuraikan sebuah disain modul "Gateway" untuk simulasi kendaraan di persimpangan lalu lintas. Gateway dirancang untuk mensimulasikan lampu lalu lintas, khususnya lampu 
merah dan lampu hijau beserta durasi waktu masing-masing. Gateway selanjutnya akan diterapkan pada aplikasi SimEvents MATLAB Simulink [3]. Durasi waktu satu siklus lampu lalu lintas didefinisikan sebagai lamanya waktu menyala lampu merah hingga akhir menyala lampu hijau. Pola kedatangan kendaraan diasumsikan mengikuti proses Poisson dengan waktu layanan berdistribusi eksponensial. Model antrian ini dikenal dengan model M/M/1, yaitu kedatangan dan pelayanan/hambatan kendaraan merupakan kejadian stokastik dengan melalui satu sistem layanan [4-7].

Berbagai kajian dan penelitian telah dilakukan untuk meningkatkan kualitas lalu lintas, dimana salah satunya adalah kelancaran perjalanan tanpa kemacetan. Analisis lalu lintas di jalan raya sangat mirip kajiannya dengan analisis lalu lintas paket data atau Internet, sehingga seringkali berapa metode manajemen lalu lintas data diterapkan pada manajemen lalu lintas jalan raya [8-11]. Kajian melalui simulasi dipandang lebih efektif, karena dapat memprediksi kejadian lalu lintas dilapangan disertai dengan rekayasa $[12,13]$. Beberapa jenis rekayasa yang dapat diterapkan diantaranya adalah sistem penyeimbangan beban (load balancing) [8,9], ganjil genap, penyempitan satu jalur, electronic road pricing (ERP), atau pengurangan penggunaan kendaraan melalui kerjasama transportasi online.

\section{Landasan Teoritis}

Sistem antrian dapat dideskripsikan sebagai kedatangan kendaraan kemudian mengantri karena terdapat hambatan dan akhirnya meninggalkan antrian. Pola kedatangan adalah salah satu unsur dasar pada model antrian. Pola kedatangan kendaraan dapat dipandang dari waktu antar kedatangan dua kendaraan yang berurutan (interarrival time) yang dapat bersifat deterministic ataupun stokastik. Pola kedatangan dikatakan deterministik apabila tetap atau tidak berubah sedemikian sehingga dapat ditentukan waktu kedatangan diantara tiap kendaraan. Kedatangan deterministik berakibat pada panjang antrian yang tetap. Pola kedatangan lainnya adalah pola stokastik, dimana waktu kedatangan antar kendaraan adalah tidak tetap atau tidak pasti dan dapat dicari dengan suatu formula tertentu berdasarkan pada suatu nilai distribusi. Dengan pola kedatangan yang tidak tetap terhadap waktu, maka panjang antrian juga tidak tetap.

Pelayanan (server) pada sistem antrian hal jumlah layanan dapat dibagi kedalam dua kategori, yaitu pelayanan tunggal atau jamak. Jumlah layanan tergantung pada banyaknya kedatangan kendaraan. Contoh otentik adalah antrian kendaraan pada pintu jalan tol. Jika jumlah kedatangan rendah, maka cukup digunakan satu layanan pintu. Namun apabila terjadi kedatangan yang tinggi, agar tidak menimbulkan antrian panjang, maka pintu layanan harus bekerja lebih cepat. Dilain pihak, jika kecepatan layanan memiliki rata-rata tertentu, maka untuk menghindari antrian kendaraan, dapat dibuka pintu layanan lainnya dimana jumlah layanan disesuaikan dengan jumlah kedatangan.

Pada penelitian ini diasumsikan antrian lalu lintas mengikuti model antrian $\mathrm{M} / \mathrm{M} / 1$, yaitu sistem antrian Markov dimana kedatangan dan layanan kendaraan dikatakan stabil dengan rata-rata tertentu. Kedatangan kendaraan diasumsikan mengikuti proses Poisson, waktu layanan diasumsikan mengikuti distribusi eksponensial, dan diasumsikan menggunakan layanan tunggal. Karakteristik dari sistem antrian Markov adalah ergodic, yaitu akan memiliki karakteristik yang sama pada rent ang waktu yang cukup panjang, dan sistem antrian berada pada kondisi steady state. Kedatangan kendaraan dilambangkan dengan variabel $\lambda$, dan layanan adalah $\mu[14,15]$.

Pada model M/M/1, rata-rata jumlah kendaraan $(N)$ didalam sistem dirumuskan sebagai

$$
N=\frac{\rho}{1-\rho}=\frac{\lambda}{\mu-\lambda}
$$


dimana $\rho$ adalah utilization atau tingkat kepadatan kendaraan dengan rentang nilai diantara 0 dan 1 . Untuk model M/M/1, nilai $\rho$ harus kurang dari 1. Rata-rata waktu kendaraan menunggu dalam sistem (T) dirumuskan sebagai

$$
T=\frac{N}{\lambda}=\frac{1}{\mu-\lambda}
$$

dan rata-rata jumlah kendaraan dalam sistem dirumuskan dengan

$$
Q=\frac{\lambda^{2}}{\mu(\mu-\lambda)}
$$

\section{Metode}

Pada artikel ini, rancangan model dan komponen-komponen untuk simulasi persimpangan lalulintas disusun menggunakan aplikasi SimEvents MATLAB [3]. SimEvents telah digunakan sebagai alat untuk mensimulasikan suatu sistem diberbagai bidang, diantaranya adalah simulasi Transportasi [12,16], Internet [17] yang melibatkan metode aliran data pada teknologi CDN dan Service-oriented Router [18-23]. Beberapa metode dapat digunakan pada simulasi pendistribusian kendaraan, diantaranya adalah load balancing [21] dan juga artificial intelligence dengan menggunakan metode Bayesian networks [8,24].

Selain SimEvents, simulator lainnya yang umum digunakan adalah ns3 [20]. Komponen-komponen penyusun sistem simulator menggunakan SimEvents ini adalah modul-modul berupa generator entity sebagai media pembangkit kedatangan kendaraan, modul server sebagai media layanan, modul gate sebagai representasi persimpangan lalu lintas, link sebagai representasi jalur transportasi, dan modul sink untuk pembuangan data.

Pelaksanaan disain sistem simulasi dilakukan melalui beberapa tahap, yaitu diawali dengan menentukan batasan dan asumsi sistem, pola distribusi kendaraan, membangun model secara konsep dengan diagram, menyusun disain model sistem dengan software SimEvents, menentukan jumlah entity data, dan menjalankan simulasi

\section{Pembahasan}

Disain sistem simulator persimpangan dengan lampu lalu lintas ditunjukkan pada Gambar 1. Simulator ini dibangun dengan menggunakan aplikasi SimEvents MATLAB. 


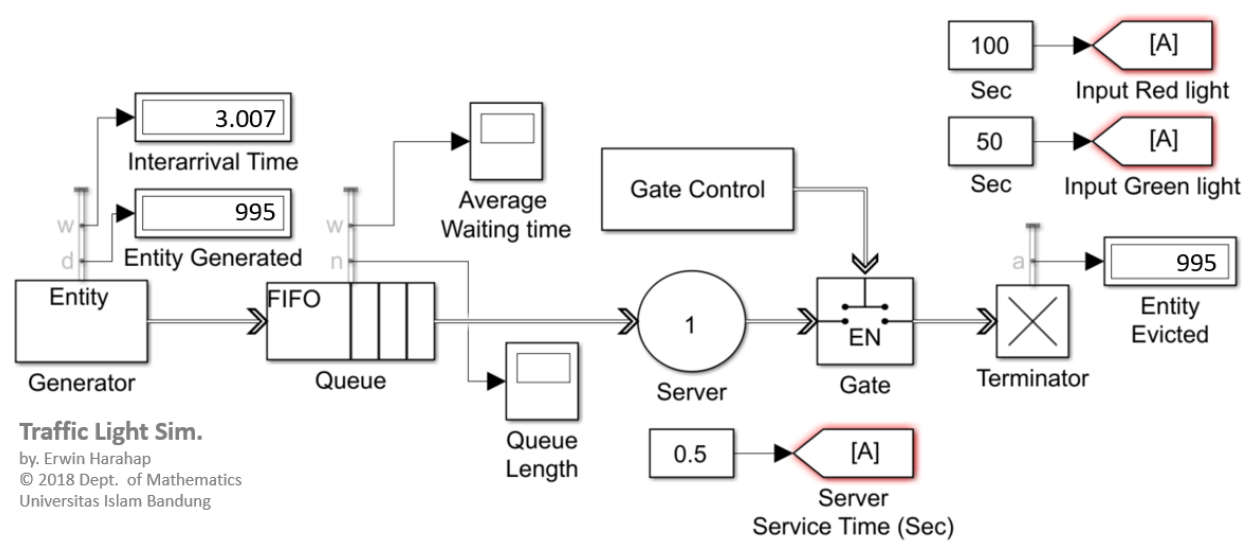

Gambar 1. Disain modul Gateway persimpangan lampu lalu lintas menggunakan SimEvents

Selanjutnya akan dibahas mengenai bagaimana modul Gateway bekerja. Proses kedatangan kendaraan diasumsikan Poisson dengan rata-rata laju kedatangan $\lambda$ (lambda), diatur dalam blok "Generator" dengan prinsip antrian M/M/1 sebagaimana dijelaskan pada sesi sebelumnya. Nilai lambda dapat diatur sesuai dengan situasi di jalan raya dan diinputkan melalui coding program pada jendela Block Parameters Entity Generator pada tab Entity Generation ditampilkan pada Gambar 2.

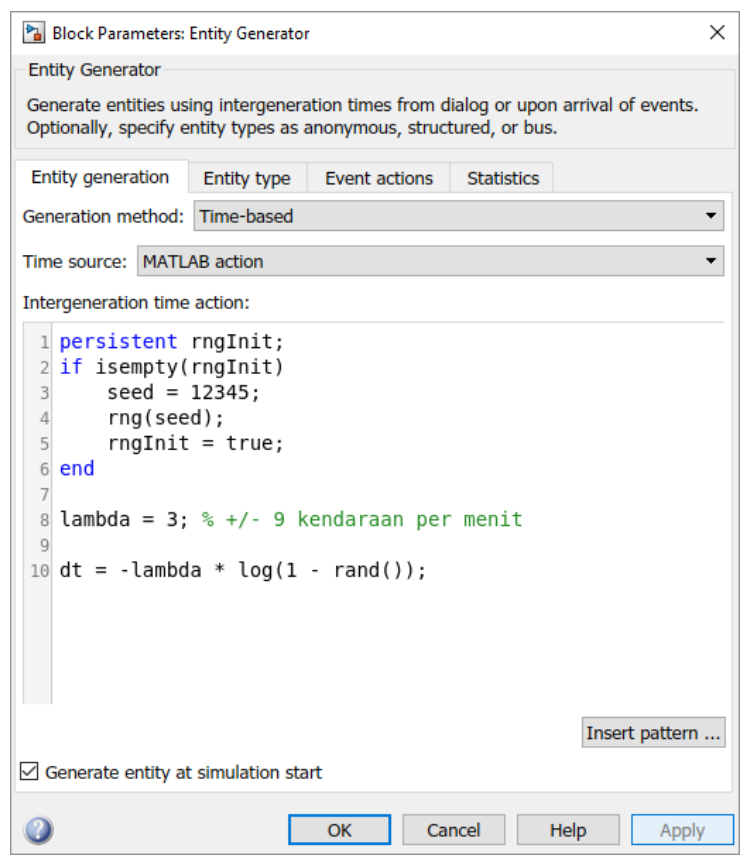

Gambar 2. Parameter pembangkit entitas rata-rata kedatangan kendaraan

Pada artikel ini, diasumsikan nilai lambda $=3$, yang memberikan pengertian bahwa rata-rata laju kedatangan kendaraan ke persimpangan adalah $1 / 3$ kendaraan per detik, atau rata-rata 9 kendaraan per menit. Total simulasi yang dijalankan adalah selama 50 menit yang menghasilkan rata-rata kedatangan sebanyak 995 kendaraan.

Selanjutnya kendaraan memasuki area atau persimpangan dengan lampu lalu lintas. Kendaraan diasumsikan berhenti karena lampu merah dan melakukan antrian. Proses menunggu didalam antrian diatur pada blok "FIFO Queue", dimana kendaraan mengantri sesuai dengan kedatangan. Batas total 
antrian dapat diatur pada block parameters entity queue (Gambar 3) dimana pada modul ini dibatasi maksimal antrian adalah 1000 kendaraan.

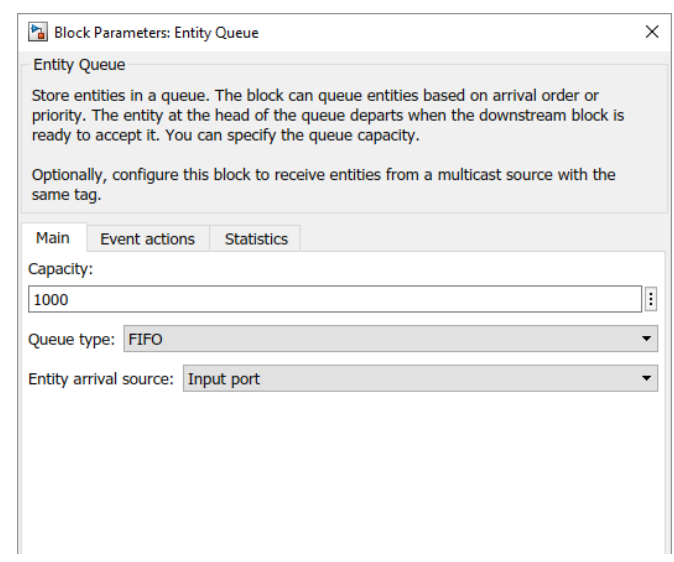

Gambar 3. Parameter pembangkit entitas rata-rata kedatangan kendaraan

Durasi waktu lampu merah dan lampu hijau diatur pada modul Gate Control dengan mekanisme buka-tutup jalur. Saat lampu hijau menyala, modul Gate akan terbuka dan kendaraan bergerak meninggalkan persimpangan. Laju rata-rata kendaraan bergerak keluar meninggalkan persimpangan adalah $\mu$ (mu), dimana nilai $\mu$ diinputkan pada Server's service time. Pada modul Gateway ini, diasumsikan durasi waktu lampu merah adalah 100 detik dan lampu hijau adalah 50 detik. Algoritma/coding modul Gateway diinputkan pada block parameters entity gateway sebagaimana ditampilkan pada gambar 4.

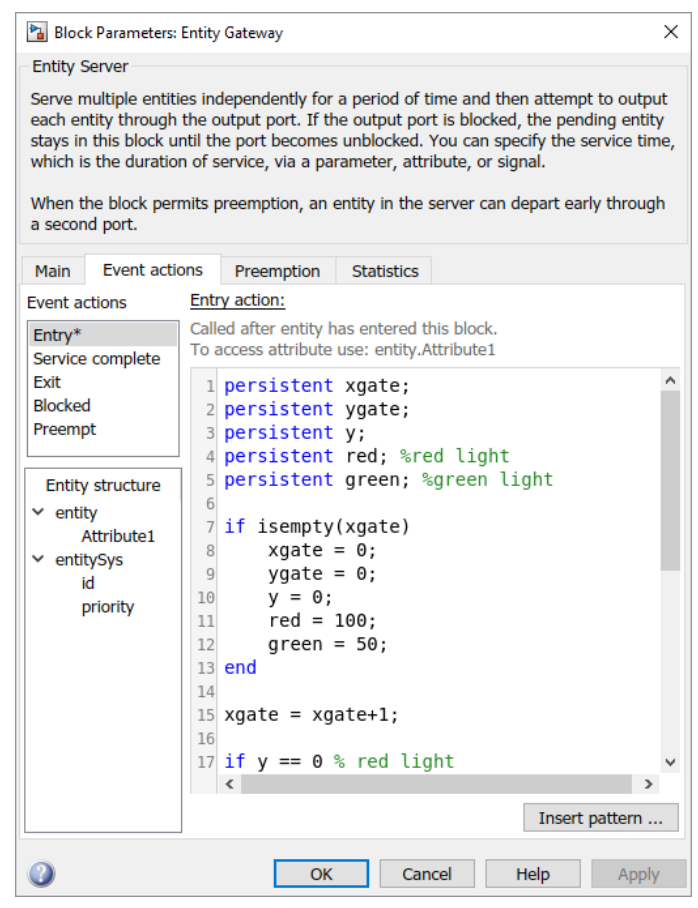

Gambar 4. Algoritma modul Gateway untuk durasi waktu lampu merah dan lampu hijau

Selanjutnya pada blok Server diatur tentang berapa banyak laju rata-rata kendaraan $\mu(\mathrm{mu})$ meninggalkan persimpangan. Pada modul ini diasumsikan bahwa pada saat menyala lampu hijau, laju rata-rata kendaraan meninggalkan kendaraan adalah $\mu=0.2856$ atau rata-rata 210 kendaraan per menit (3.5 kendaraan per detik). Parameter nilai $\mu$ dapat diatur pada jendela blok parameters entity server yang ditunjukkan pada gambar 5 . 


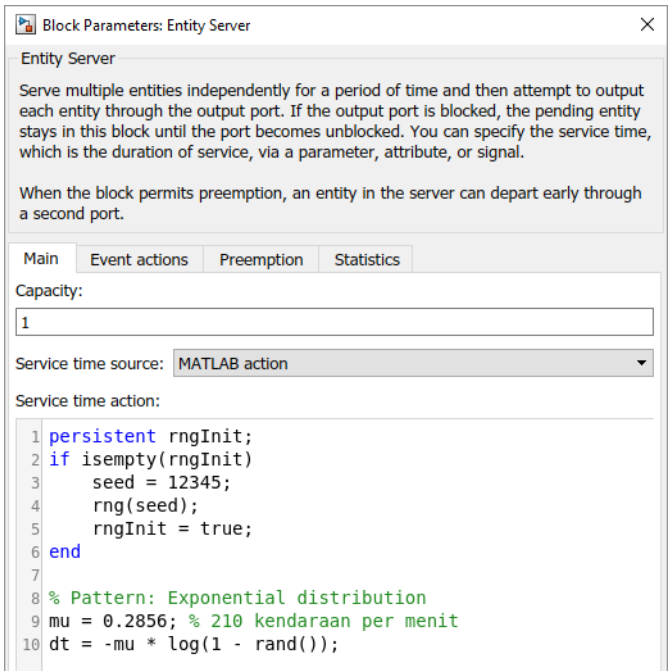

Gambar 5. Setting parameter nilai laju rata-rata kendaraan keluar dari persimpangan

Output yang dirancang untuk hasil simulasi modul Gateway ini adalah panjang antrian kendaraan (Queue-length) dan rata-rata waktu menunggu didalam antrian di persimpangan (Average waiting time). Queue-length dapat diperoleh dengan mengaktifkan fungsi pada modul "Queue-length", dan rata-rata waktu menunggu dalam antrian dapat diperoleh dengan mengaktifkan fungsi terkait pada modul "Average waiting time".

\section{Kesimpulan}

Modul Gateway adalah salah satu metode yang dapat digunakan untuk mensimulasikan persimpangan jalan raya dengan lampu lalu lintas. Melalui modul ini diharapkan dapat diperoleh waktu yang tepat untuk durasi lampu merah dan lampu hijau sedemikian sehingga diperoleh keseimbangan antrian kendaraan di setiap jalur. Saran untuk penelitian lebih lanjut adalah dengan membangun modul sesuai dengan jumlah persimpangan dan dilakukan simulasi berdasarkan pada real data di jalan raya.

\section{Referensi}

[1] Rakyat Merdeka Online, "Atasi kemacetan, Pemerintah Harus Berani Batasi Kendaraan," Kantor Berita Politik RMOL.co, 22 September 2016. [Online]. Available: http://rmol.co.

[2] Oke News, "Gawat! Kepadatan Lalu Lintas Yogyakarta Dekati Titik Jenuh", news.okezone.com, 30 September 2017. [online]

[3] "SimEvents: Model and simulate discrete-event systems," MathWorks, 2018. [Online]. Available: https://www.mathworks.com/products/simevents.html. [Accessed 27 Februari 2018].

[4] Hamdy A. Taha, "Queuing Models," in Operation Research, Bandung, Binarupa Aksara, 1997, pp. 178-181.

[5] E. Harahap, F. H. Badruzzaman and M. Y. Fajar, "Model dan Simulasi Sistem Transportasi Dengan Teori Antrian," Matematika - Jurnal Teori dan Terapan Matematika, vol. 15, no. 1, 2016.

[6] Rouphail, Nagui., Tarko, Andrzej., \& Li, Jing., Traffic Flow at Signalized Intersections, Traffic Flow Theory Monograph, Chapter 9., 2001.

[7] M. T. S. Gauss, "Delay Model on Signalized Intersection," Mathematics Department. Universitas Indonesia., Depok, 2010.

[8] E Harahap, et. al., "Efektifitas Load Balancing Dalam Mengurangi Kemacetan Jalan Raya," Jurnal Matematika UNISBA, vol. 16, no. 2, 2017.

[9] E. Harahap, I. Sukarsih, H. Farid and M. Y. Fajar, "Model Antrian Dengan Pengalihan Dinamis untuk Mengurangi Kemacetan Jalan Raya," ETHOS (Jurnal Penelitian dan Pengabdian), vol. 5, no. 2, pp. 182-185, 2017. 
[10] E Harahap, J Wijekoon, R Tennekoon, F Yamaguchi, H Nishi, "Router-based request redirection management for a next-generation content distribution network," in GC13 WS - MENS: Globecom 2013 Workshop, Atlanta, USA, 2013.

[11] E. Harahap, J. Wijekoon, R. Tennekoon, F. Yamaguchi, S. Ishida and H. Nishi, "A router-based management system for prediction of network congestion," in Advanced Motion Control (AMC), 2014 IEEE 13th International Workshop on, Yokohama, Japan., 2014.

[12] E Harahap, A Harahap, A Suryadi, D Darmawan, R Ceha, "LINTAS: Sistem simulasi lalu lintas menggunakan SimEvents MATLAB," Jurnal Ilmiah Informatika dan Komputer (ISSN: 2339-188X), vol. 10, no. 1, pp. 8-16, 2018.

[13] M. R. Fadhillah, I. Sukarsih and E. Harahap, "Simulasi Pengaturan Lampu Lalu Lintas Menggunakan Fuzzy Inference System Metode Mamdani pada MATLAB," Matematika: Teori dan Terapan Matematika, vol. 16, no. $1,2017$.

[14] Gunter Bolch, Stefan Greiner, Hermann de Meer, Kishor S. Trivedi, Queueing Networks and Markov Chains 2nd, New Jersey, USA.: John Wiley \& Sons, Inc., 2006.

[15] Ng Chee-Hock, Soong Boon-Hee, Queueing Modelling Fundamentals 2nd, Sussex, England.: John Wiley \& Sons Ltd., 2008.

[16] E. Harahap, A. A. Nurrahman and D. Darmawan, "A Modeling Approach For Event-Based Networking Design Using MATLAB-SimEvents," in International Multidisciplinary Conference (IMC) 2016, Jakarta, Indonesia, 2016.

[17] E. Harahap, I. Sukarsih, G. Gunawan, M. Y. Fajar, D. Darmawan and H. Nishi, "A Model-Based Simulator for Content Delivery Network using SimEvents MATLAB-Simulink," INSIST: International Series on Interdisciplinary Science and Technology, vol. 1, no. 1, pp. 30-33, 2016.

[18] J Wijekoon et. al., "Effectiveness of Service-oriented router for ISP-CDN collaboration," Journal of Information Processing, vol. 25, pp. 45-55, 2017.

[19] J Wijekoon et. al., "How can a service-oriented router merge with a cdn?," IEEJ Transactions on Electronics, Information and Systems, vol. 136, no. 8, 2016. pp. 1172-1179.

[20] J Wijekoon, R Tennekoon, E Harahap, H Nishi, "Service-oriented router module implementation on ns-3," in SIMUTOOLS 2014: The 7th International ICST Conference on Simulation Tools and Techniques, 2014.

[21] R Tennekoon, J Wijekoon, E Harahap, H Nishi, E Saito, S Katsura, "Per hop data encryption protocol for transmission of motion control data over public networks," in IEEE 13th International Workshop on Advanced Motion Control (AMC), Yokohama, Japan., 2014. pp. 128-133

[22] R Tennekoon, J Wijekoon, E Harahap, H Nishi, "Per-hop data encryption protocol for transmitting data securely over public networks," Procedia Computer Science, vol. 32, pp. 965-972, 2014.

[23] E. Harahap, J. Wijekoon, R. Tennekoon, F. Yamaguchi, S. Ishida and H. Nishi, "Distributed algorithm for router-based management of replica server in next-CDN infrastructure," in Cyber-Enabled Distributed Computing and Knowledge Discovery (CyberC), 2013 International Conference on, Beijing, China., 2013.

[24] E. Harahap, W. Sakamoto and H. Nishi, "Failure prediction method for network management system by using Bayesian network and shared database," in Information and Telecommunication Technologies (APSITT), 2010 8th Asia-Pacific Symposium on, Kota Kinabalu, Malaysia., 2010. 